\title{
Traditional Chinese Medicine (TCM) Astragalus Membranaceus and Curcuma Wenyujin Promote Vascular Normalization in Tumor-derived Endothelial Cells of Human Hepatocellular Carcinoma
}

\author{
WENHUA ZANG ${ }^{1,2}$, HUA BIAN ${ }^{1,2}$, XIANZHANG HUANG $^{1,2}$, GANG YIN $^{3}$, \\ CHAOYUN ZHANG ${ }^{1,2}$, LI HAN $^{1,2}$, PENGFEI HAO ${ }^{1,2}$, SHENGCHEN DING ${ }^{1,2}$, \\ YU SUN ${ }^{4}$, ZHIJIAN YANG ${ }^{4,5}$, ROBERT M. HOFFMAN ${ }^{5,6}$ and DECAI TANG ${ }^{3}$ \\ ${ }^{I}$ Zhang Zhongjing College of Traditional Chinese Medicine, Nanyang Institute of Technology, Nanyang, P.R. China; \\ ${ }^{2}$ Henan Key Laboratory of Zhang Zhongjing Formulae and Herbs for Immunoregulation, Nanyang, P.R. China; \\ ${ }^{3}$ Nanjing University of Chinese Medicine, Nanjing, P.R. China; \\ ${ }^{4}$ Origin Biosciences Inc., Nanjing, P.R. China; \\ ${ }^{5}$ AntiCancer, Inc., San Diego, CA, U.S.A.; \\ ${ }^{6}$ Department of Surgery, University of California, San Diego, CA, U.S.A.
}

\begin{abstract}
Background/Aim: The aim of the present study was to investigate the vascular normalization effect of traditional Chinese medicine Astragalus membranaceus (AM) and Curcuma wenyujin $(\mathrm{CW})$ on tumor-derived endothelial cells (TECs). Materials and Methods: TECs were isolated from the xenografted HCC cell line HepG2 expressing red fluorescent protein (RFP). The effect of $A M$ and $C W$ on TECs proliferation was measured using the CCK8 assay. The vascular normalization potential of $A M$ and $C W$ was assessed using a tube formation assay. Immunocytochemistry was performed to assess the effect of $A M$ and $C W$ on the expression of angiogenic maker CD34 and hypoxia-inducible factor HIFla. Results: The isolated TECs and endothelioma (EOMA) cells did not differ with regard to the expression levels of endothelial markers CD34, VEGFR-1,VEGFR-2, PDGFR- $\alpha$ and PDGFR- $\beta$. All AM, CW, AM+CW and Nintedanib (Nin) showed a dose-dependent increasing inhibition effect on either TECs or EOMA cells. AM, CW and $A M+C W$ significantly reduced HIF la expression, increased
\end{abstract}

This article is freely accessible online.

Correspondence to: Hua Bian, Zhang Zhongjing College of Traditional Chinese Medicine, Nanyang Institute of Technology, Nanyang, PR China. Tel: +86 37762071311, e-mail: biancrown@163.com; Decai Tang, Nanjing University of Chinese Medicine, Nanjing, PR China. Tel: +86 2585811924, e-mail: talknow@163.com

Key Words: Astragalus membranaceus, Curcuma wenyujin, agiogenesis, vascular normalization, HCC.
CD34 expression and enhanced endothelial network formation in TECS or EOMA cells compared to the control. Conclusion: $A M$ and $C W$ promoted vascular normalization in tumor-derived endothelial cells of HCC, through increased expression of CD34 and reduced expression of HIF 1 a.

Hepatocellular carcinoma (HCC) is the most frequent malignancy in Asia and is refractory to most therapies (1). HCC angiogenesis correlates with prognosis (2). Survival in HCC has been increased by angiogenesis inhibitors, including sorafenib (3) and bevacizumab (4), which selectively starve tumors by preventing or reducing neovasculature formation (5-7). However, some antiangiogenic compounds can promote the normalization of immature and disorganized vessels in tumors (8-10), which may enhance tumor oxygenation or delivery of therapeutic compounds $(11,12)$. Further investigation is required to explore the effect of antiangiogenic compounds on vessel-normalization.

Astragalus membranaceus $(A M)$ and Curcuma wenyujin $(C W)$ are traditional Chinese medicines (TCM) widely prescribed in the clinical treatment of many indications including cancer therapy. AM and $\mathrm{CW}$ had significant growth-inhibitory, proapoptotic or anti-angiogenic properties on many types of cancers including HCC (13-18). Our previous study demonstrated the combined anti-tumor and anti-angiogenic efficacy of $A M$ and $C W$ in ovarian cancer in vitro and in vivo $(19,20)$.

In the present study, tumor-derived endothelial cells (TECs) derived from a human HCC mouse model were isolated and characterized. These TECs were used to assess the vascular normalization effects of AM and $\mathrm{CW}$ including 
their potential to enhance endothelial network formation and oxygenation.

\section{Materials and Methods}

Cells. The endothelioma (EOMA) cell line was purchased from American Type Culture Collection (ATCC). The human hepatocellular carcinoma (HCC) cell line HepG2 expressing red fluorescent protein (RFP) was obtained from AntiCancer, Inc. (San Diego, CA, USA). EOMA and HepG2-RFP cells were cultured in RPMI-1640 medium (GIBCO, Grand Island, NY, USA) with $10 \%$ calf serum (Hyclone, Logan, UT, USA) plus $1 \%$ penicillin and streptomycin at $37^{\circ} \mathrm{C}$ in a $5 \% \mathrm{CO}_{2}$ atmosphere.

Xenograft tumor model of HCC. BALB/C female nude mice, aged 4-6 weeks and weighing 20-25g, were purchased from the Yang Zhou University Laboratory Animal Center (SCXK, Su. 20160024). All mice were maintained in a HEPA-filtered environment at 24$25^{\circ} \mathrm{C}$ and humidity was maintained at $50-60 \%$. All animals were fed with autoclaved laboratory rodent diet. Animal experiments were approved by the Animal Committee of Nanjing Origin Biosciences, China (OB1611).

HepG2-RFP cells were treated while in the logarithmic phase of growth with $0.25 \%$ trypsin (GIBCO, Grand Island, NY, USA). HepG2-RFP cells, $\left(5 \times 10^{6}\right)$ suspended in $200 \mu$ serum-free RPMI1640 , were subcutaneously injected into the right flank of nude mice. Tumors were excised for tumor tissue collection when tumor volume reached $1000 \mathrm{~mm}^{3}$.

Isolation of tumor derived endothelial cells. Tumor derived endothelial cells (TECs) were obtained from the tumors resected from xenograft tumor model of HCC. Tumor specimens were placed in cold DMEM medium (Gibco). Peripheral and necrotic tissues were excised and the remaining tumor was minced into approximately 1-2 $\mathrm{mm}^{3}$ fragments with scissors. The fragments were incubated in DMEM medium containing $0.1 \%$ Collagenase IV (Sigma) and $0.02 \%$ DNAse at $37^{\circ} \mathrm{C}$ in a $5 \% \mathrm{CO}_{2}$ atmosphere for 1 $\mathrm{h}$. Then the fragments were placed in a culture flask with EGM2MV (Lonza) medium containing 15\% calf serum (Hyclone, Logan, UT, USA) and cultured at $37^{\circ} \mathrm{C}$ in a $5 \% \mathrm{CO}_{2}$ atmosphere. Medium change was performed every 3-4 days. Confluent cells were washed once with PBS, detached by using $0.25 \%$ trypsin and passaged by a ratio of maximal 1:3. After 3 passages, TECs clones without fluorescence were selected by limited dilution in 96-well plates.

Flow cytometric analysis. Isolated TECs were characterized by flow cytometric analysis. EOMA cells were used for comparison. Cells were detached from plates with $0.25 \%$ trypsin and washed in PBS containing $0.5 \%(\mathrm{w} / \mathrm{v})$ bovine serum albumin (BSA). Cells were then incubated for $30 \mathrm{~min}$ at $4^{\circ} \mathrm{C}$ with the appropriate antibody including FITC conjugated anti-CD34 antibody and PE conjugated anti-VEGFR-1, VEGFR-2, PDGFR- $\alpha$ and PDGFR- $\beta$ antibodies. Cells were analyzed on a fluorescence activated cell sorter (Becton Dickinson, NJ, USA). All antibodies were purchased from eBioscience with the exception of VEGFR-1-PE and VEGFR-2-PE (R\&D Systems).

Cell proliferation assay. Extracts from Astragalus membranaceus $(A M)$ and Curcuma wenyujin $(C W)$ used in the study were supplied by the Nanjing University of Chinese Medicine and kept at $4^{\circ} \mathrm{C}$ until use. AM and CW extracts were dissolved and diluted with distilled water before administration. Nintedanib (Nin), a tyrosinekinase inhibitor, was from Selleck. Cell proliferation was measured using CCK 8 assay. TECs and EOMA cells $\left(3.5 \times 10^{3}\right.$ cells/well $)$ were allowed to grow in 96-well plates overnight. Before treatment, all cells were changed to serum free medium with $1 \% \mathrm{BSA}$. The cells were then divided into 4 groups and treated with $\mathrm{AM}, \mathrm{CW}, \mathrm{AM}+\mathrm{CW}$ or Nin. AM and CW were used at $0.1875,0.375,0.75,1.5,3,6$ and $12 \mathrm{mg} / \mathrm{ml}$. Mintedanib was used at 2.5, 5, 10, 20, 40 and $80 \mathrm{nM}$. Untreated cells were used as negative control. After $48 \mathrm{~h}$ treatment, $10 \mu \mathrm{l} \mathrm{CCK} 8$ reagent were added to each well for $4 \mathrm{~h}$. The optical density (OD) at $450 \mathrm{~nm}$ was determined by a microplate reader (Bio-Rad, Hercules, CA, USA). The results are presented as a percentage inhibition to the negative control. All experiments were repeated at least three times.

Tube formation assay. The vascular normalization potential of AM and $\mathrm{CW}$ was assessed using a tube formation assay. TECs and EOMA cells $\left(3.5 \times 10^{3}\right.$ cells/well $)$ were allowed to grow in 96 -well plates overnight. Before treatment, all cells were changed to serum free medium with $1 \%$ BSA. The cells were then divided into 4 groups and treated with $\mathrm{AM}, \mathrm{CW}, \mathrm{AM}+\mathrm{CW}$ or $\mathrm{Nin}$. $\mathrm{AM}$ and $\mathrm{CW}$ were used at the concentration of $0.18 \mathrm{mg} / \mathrm{ml}$. Mintedanib was used at the concentration of $5 \mathrm{nM}$. After $48 \mathrm{~h}$ treatment, all cells were collected, resuspended in EGM-2 medium and added to a 96-well plate that was precoated with basement membrane extracts (BME). After 4-6 h cultivation at $37^{\circ} \mathrm{C}$, tubes were photographed using a microscope. For each well, tube formation was quantified as the average number of tube-like structure in three wells.

Immunocytochemistry. The effect of AM and $\mathrm{CW}$ on the expression of CD34 and HIF1a was assessed with immunocytochemistry. The TECs or EOMA cells $\left(1 \times 10^{5}\right)$ were added on coverslips placed in a 6-well plate. After all cells attached to the coverslip, the cells were divided into 4 groups and treated with $\mathrm{AM}, \mathrm{CW}, \mathrm{AM}+\mathrm{CW}$ or Nin. $\mathrm{AM}$ and $\mathrm{CW}$ were used at $0.18 \mathrm{mg} / \mathrm{ml}$. Mintedanib was used at $5 \mathrm{nM}$. After $24 \mathrm{~h}$ treatment, all cells on the coverslip were washed by PBS for 3 times and fixed with $4 \%$ paraformaldehyde for 20 min. The cells were permeabilized with $0.5 \%$ Triton X-100 for 20 min and blocked with goat serum (ZSGB-BIO, Beijing, China) in phosphate-buffered saline (PBS) containing $2 \%$ bovine serum albumin for $30 \mathrm{~min}$ at room temperature. Then the cells were incubated with primary antibody against CD34 and HIF1a (Abcam, USA) at a dilution 1:200 overnight at $4^{\circ} \mathrm{C}$. After washing with $\mathrm{pH}$ 7.4 PBS, the secondary antibody (Dako REAL EnVision Detection System, Dako, Cambridgeshire, UK) was added and the incubation continued for $2 \mathrm{~h}$ at room temperature. Color development was performed with 3, 3'-diaminobenzidine (DAB). Nuclei were lightly counter stained with hematoxylin. The slides were viewed at $\times 400$ magnification and positive cells were recognized by the appearance of brown staining. The expression level was quantified by the average optical density (AOD) of the positive cells in five fields per sample with ImagePro Plus 6.0 software. (Media Cybernetics, Silver Spring, MD, USA).

Statistical analysis. All data were presented as the mean values \pm standard deviation and were analyzed using SPSS 17.0 software (Chicago, IL, USA). Comparisons between different groups were conducted using a one-way ANOVA. $p<0.05$ was considered to indicate a statistically significant difference. 

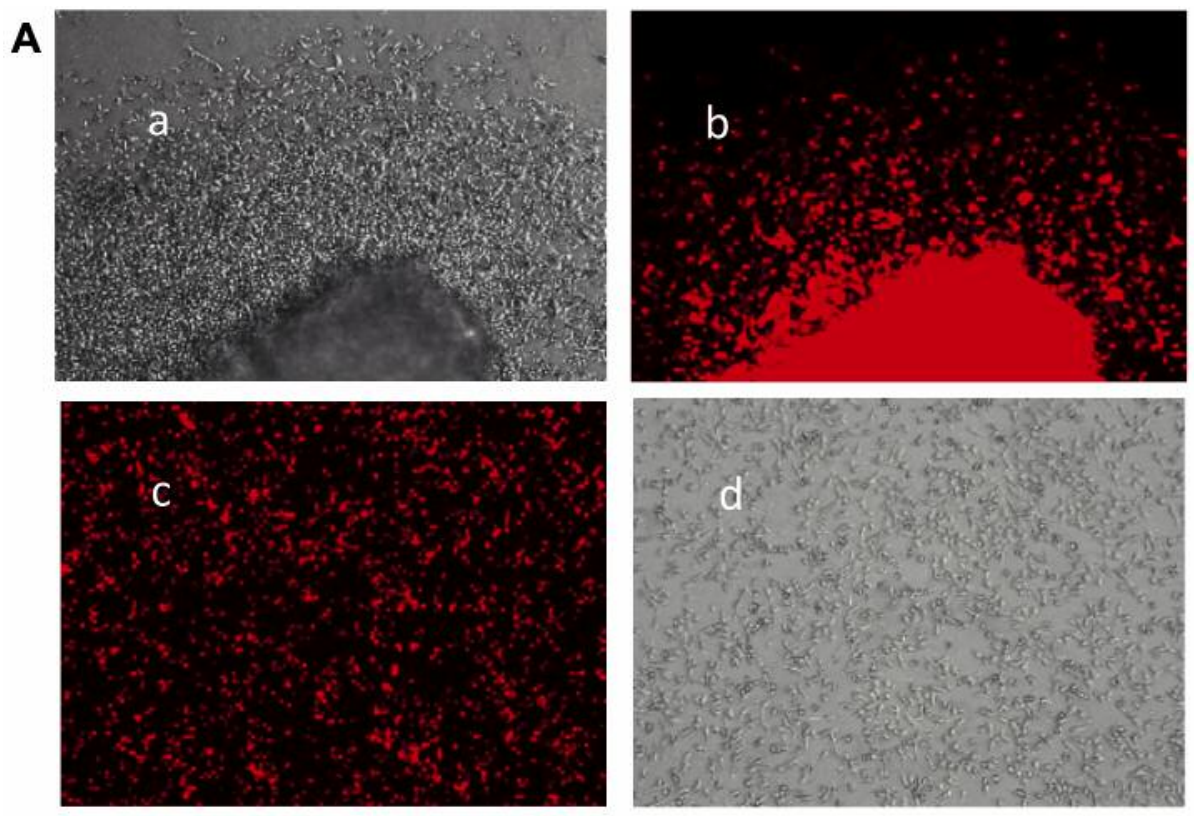

\section{B}

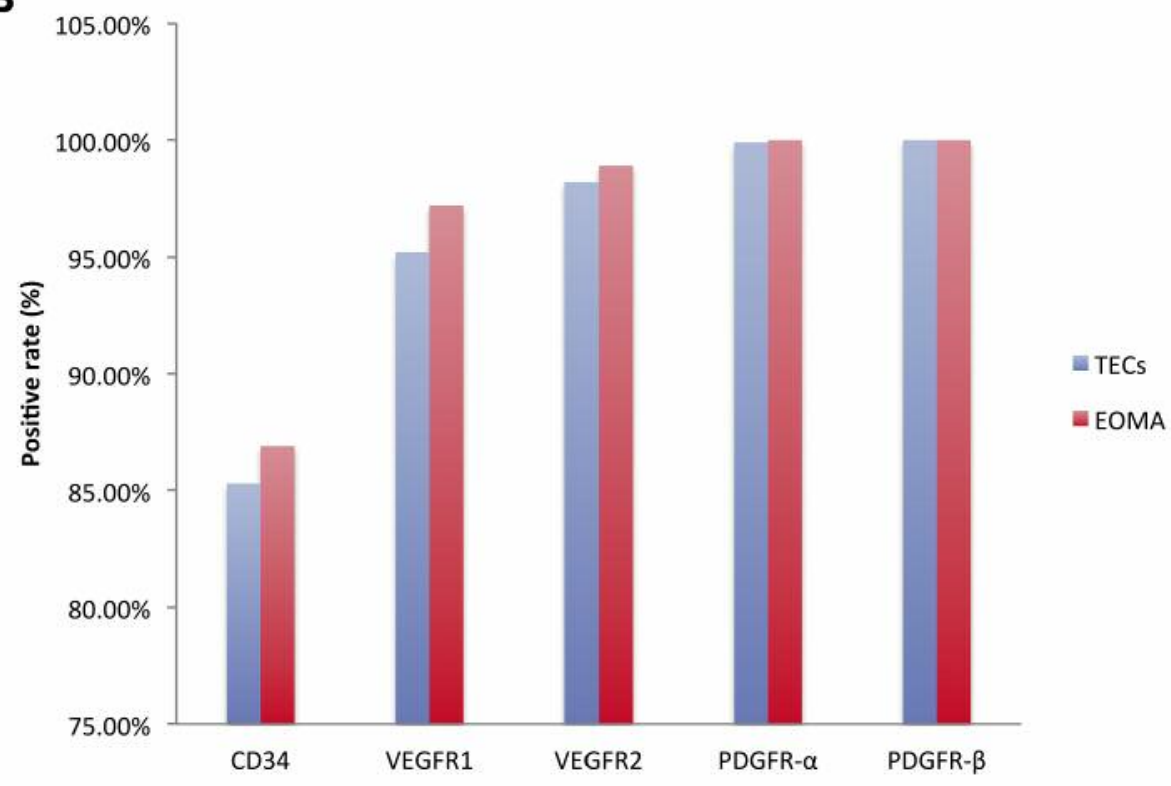

Figure 1. Isolation and characterization of TECs. TECs were isolated from a HCC xenograft tumor derived from the human cell line HepG2 expressing red fluorescent protein (RFP) and characterized by flow cytometric analysis for the expression of a panel of endothelial markers. A. Representative microphotographs of the isolated cells. (a). Bright-field imaging of the cells arose from the tumor fragment, representing a mixture of red fluorescent tumor cells, epithelial cells and other stromal cells; $(b)$. Fluorescence imaging of same field of cells that arose from the tumor fragment; (c). Fluorescence imaging of the cells after passage; (d). Bright-field imaging of TECs after limited dilution selection. Magnification $\times 100$. B. Flow cytometric analysis for the expression of a panel of endothelial markers in TECs and EOMA cells.

\section{Results and Discussion}

Isolation and characterization of TECs from a xenografted HepG2, an HCC cell line. TECs were isolated from the xenografted HCC cell line HepG2 expressing red fluorescent protein (RFP). RFP tumor cells were used in order to easily differentiate TECs from tumor cells. Harvested tumor tissue fragments were cultivated in culture flasks with EGM2-MV (Lonza) medium. Within 5-7 days, many cells with heterogeneous morphology arose from the tumor fragments, 


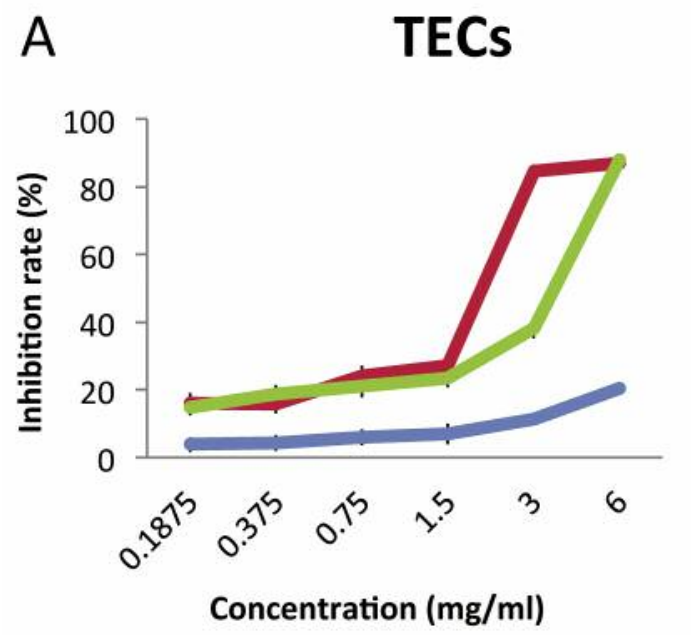

B

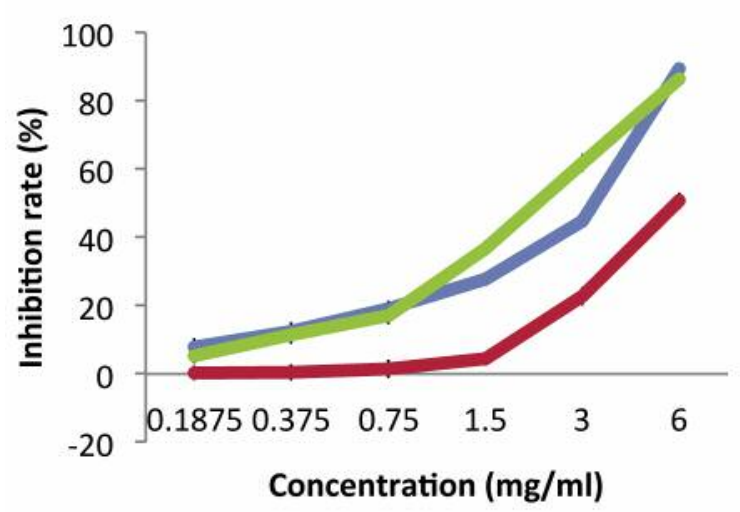

most likely representing a mixture of red fluorescent cancer cells, epithelial cells and other stromal cells [Figure 1A, (a and $\mathrm{b})]$. The mixed cells were then passaged and expanded [(Figure 1A (c)]. For isolation of TECs, TEC clones without fluorescence were selected by limited dilution in 96-well plates, resulting in pure non-fluorescent TEC culture [(Figure $1 \mathrm{~A}(\mathrm{~d})]$.

TECs were further characterized by flow cytometric analysis for the expression of a panel of endothelial markers, including CD34, VEGFR-1, VEGFR-2, PDGFR- $\alpha$ and

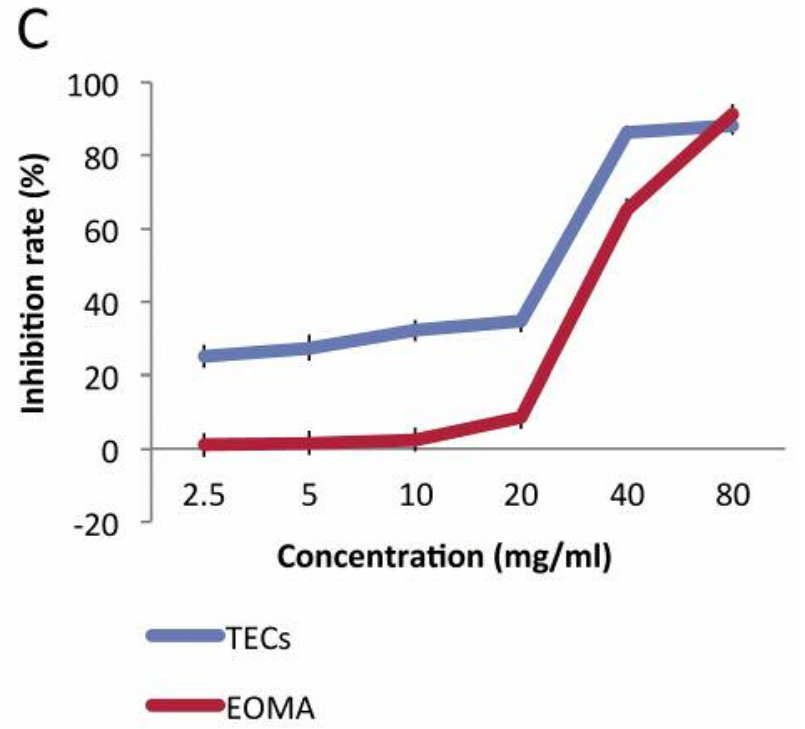

Figure 2. Effects of AM and CW on cell proliferation of TECs. Cell proliferation was measured using the $C C K-8$ assay. A. TECs proliferation inhibition by $A M, C W$ or $A M+C W ; B$. EOMA cell proliferation inhibition by $A M, C W$ or $A M+C W ; C$. TECs and EOMA cells proliferation inhibition by Nin. AM: Astragalus membranaceus; CW: Curcuma wenyujin.

PDGFR- $\beta$. The expression level of these endothelial markers was detected during cell culture. As shown in Figure 1B, FACS analysis demonstrated that the expression levels of endothelial markers in the isolated TECs were similar to those in the commercially available endothelioma cell line (EOMA).

There is evidence that TECs are more appropriate for screening anti-angiogenesis drugs than normal endothelial cells (21) because TECs possess some different characteristics as indicated by the expression of specific 'tumor endothelial markers' and cytogenetical abnormalities $(22,23)$. In this study, the isolated HCC-derived endothelial cells expressed similar levels of endothelial markers as the endothelioma cell line, suggesting that TECs possess unique features that reflect a tumor-specific specialization of the vasculature.

Effects of AM and CW on cell proliferation of TECs. The aim of this study was to investigate the anti-angiogenic potential of $\mathrm{AM}$ and $\mathrm{CW}$ by examining tumor vascular normalization. CCK-8 cell proliferation assay was performed to find the non-toxic doses of AM and CW. Nintedanib (Nin), a small molecule tyrosine-kinase inhibitor, targeting vascular endothelial growth factor receptor (VEGFR) was used as a comparison to AM and CW. As shown in Figure 2, all AM, $\mathrm{CW}, \mathrm{AM}+\mathrm{CW}$ and Nin inhibited cell proliferation of TECs 
A

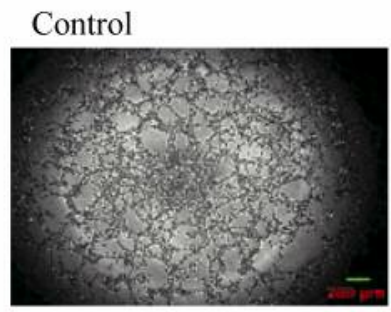

Nin

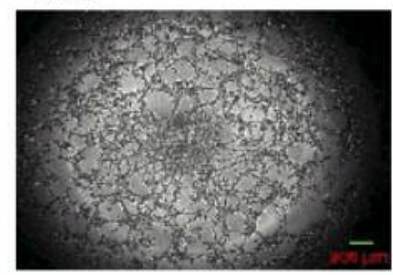

AM
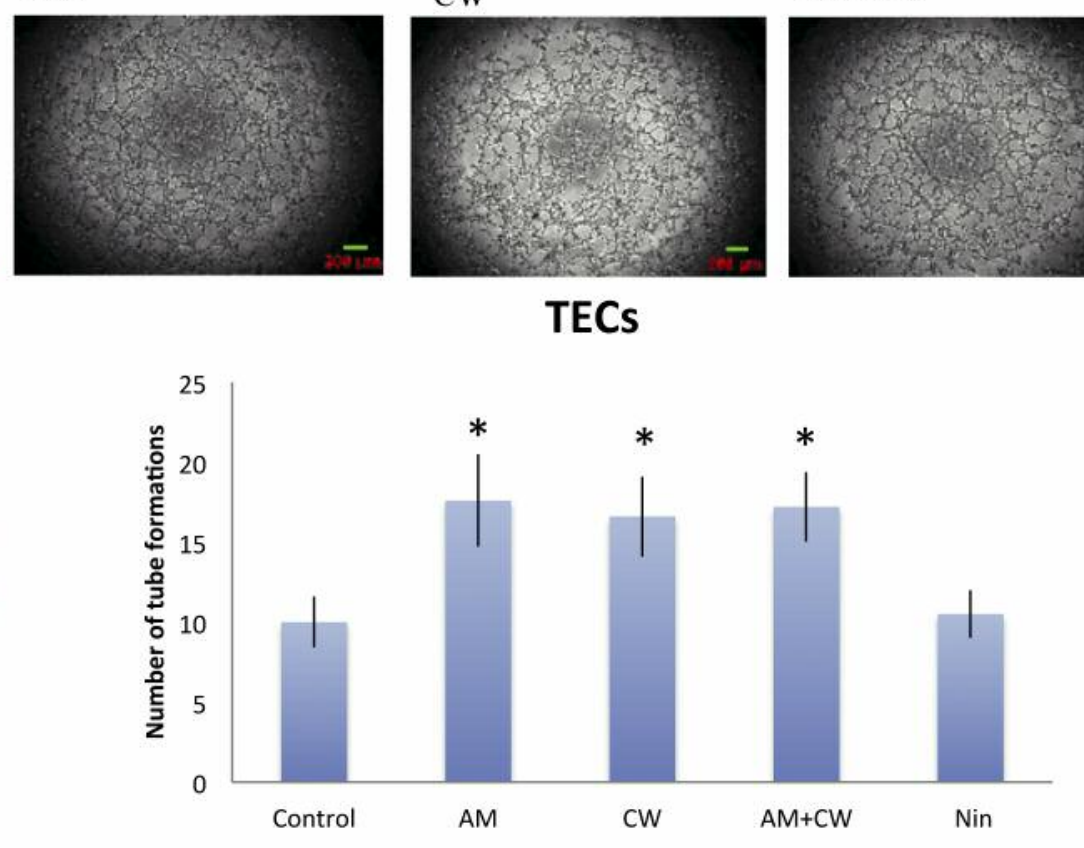

CW

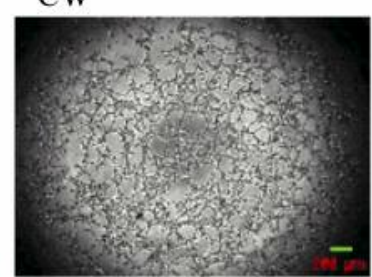

TECS

\section{$\mathrm{AM}+\mathrm{CW}$}

AM

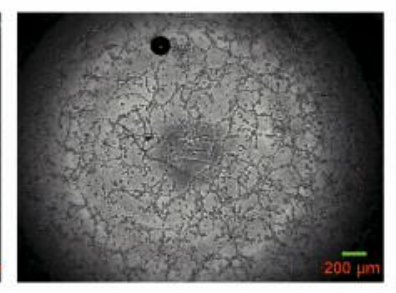

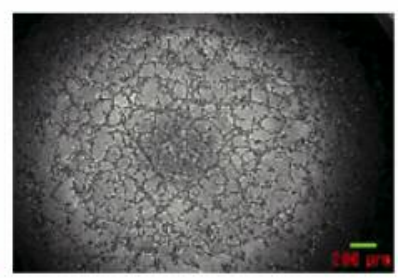
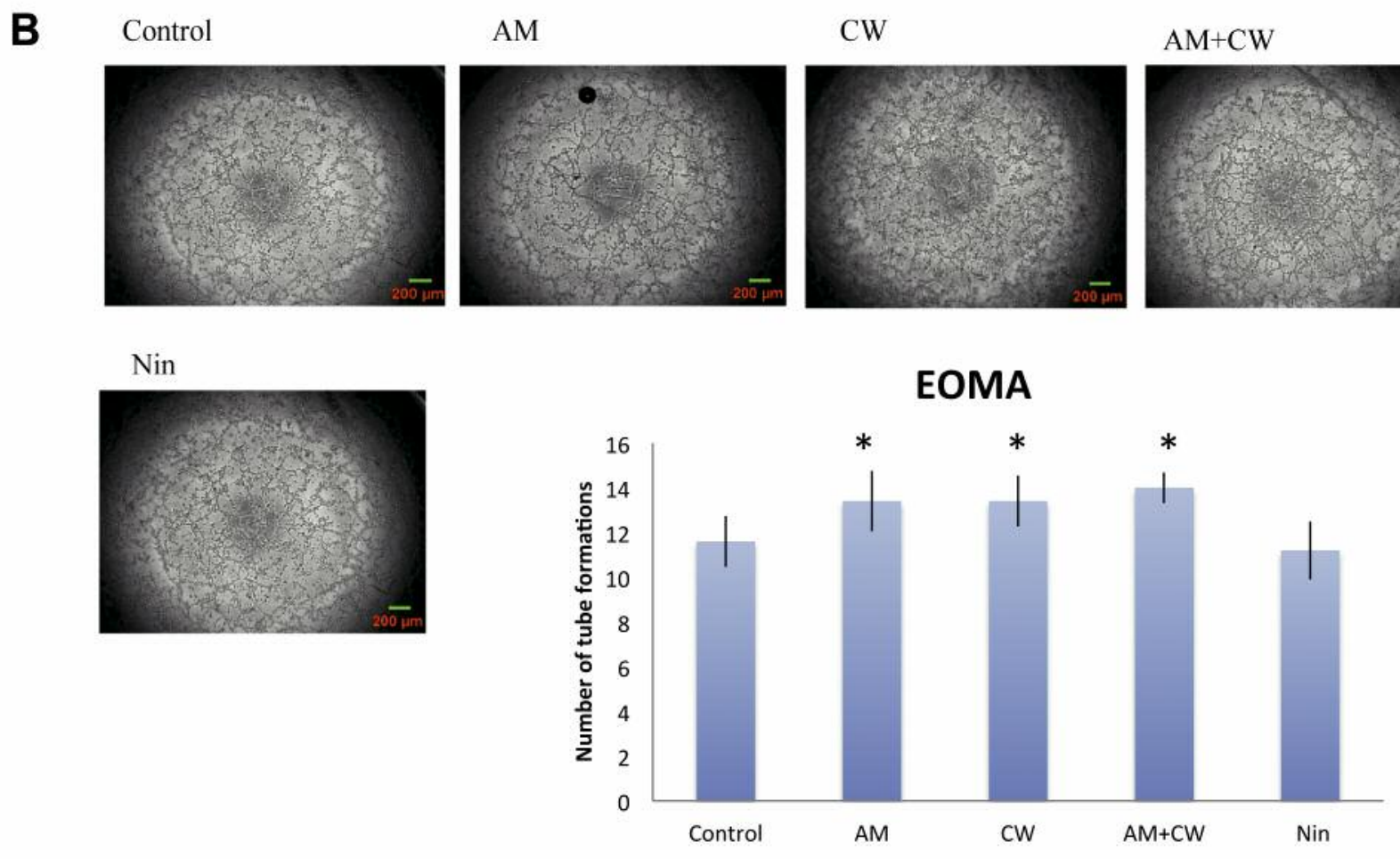

\section{$\mathrm{AM}+\mathrm{CW}$}
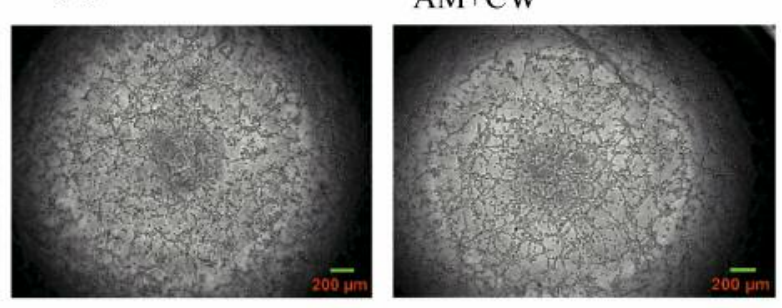

AM+CW

Figure 3. AM and CW enhanced endothelial network formation. Endothelial network formation was assessed using the tube formation assay. A. Representative microphotographs of TEC tube-like structures and quantification of tube formation number in each treatment group. B. Representative microphotographs of EOMA tube-like structure and quantification of tube formation number in each treatment group. Magnification $\times 200$. * $p<0.05$, when compared with control group. AM: Astragalus membranaceus; CW: Curcuma wenyujin; Nin: mintedanib. 
A

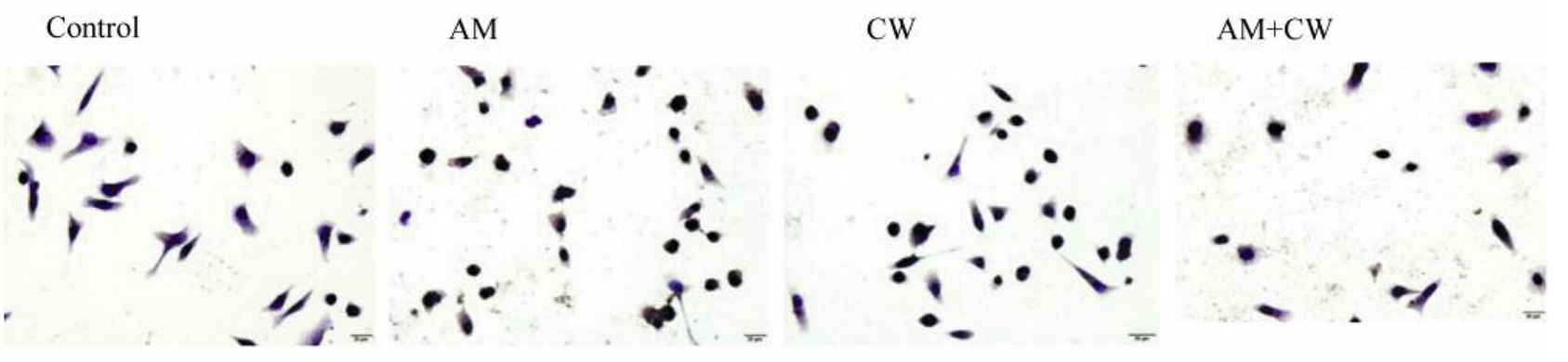

Nin

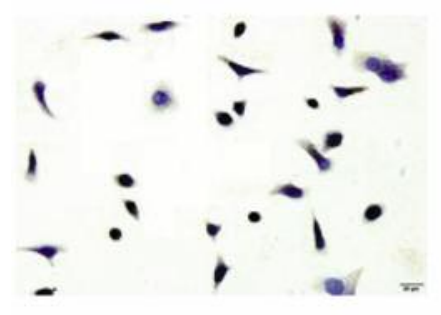

\section{TECs-CD34}

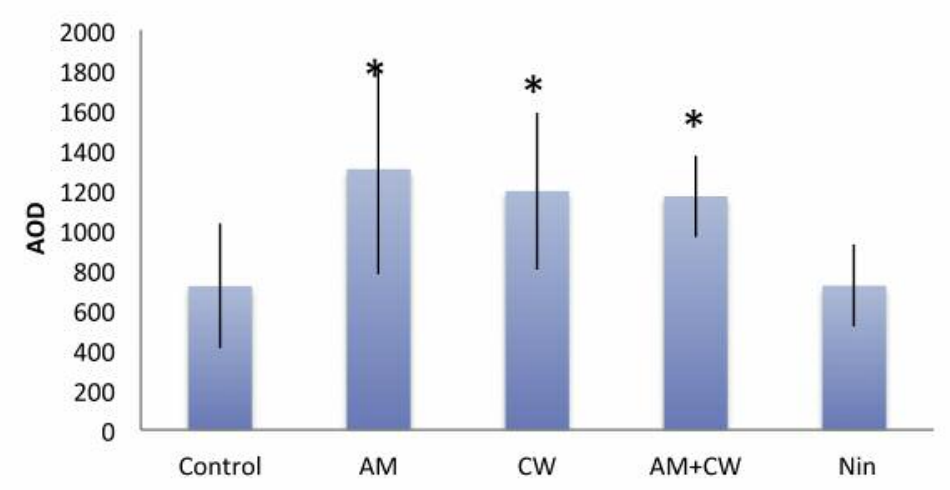

B

Control

$\mathrm{AM} \quad \mathrm{CW}$

$\mathrm{AM}+\mathrm{CW}$
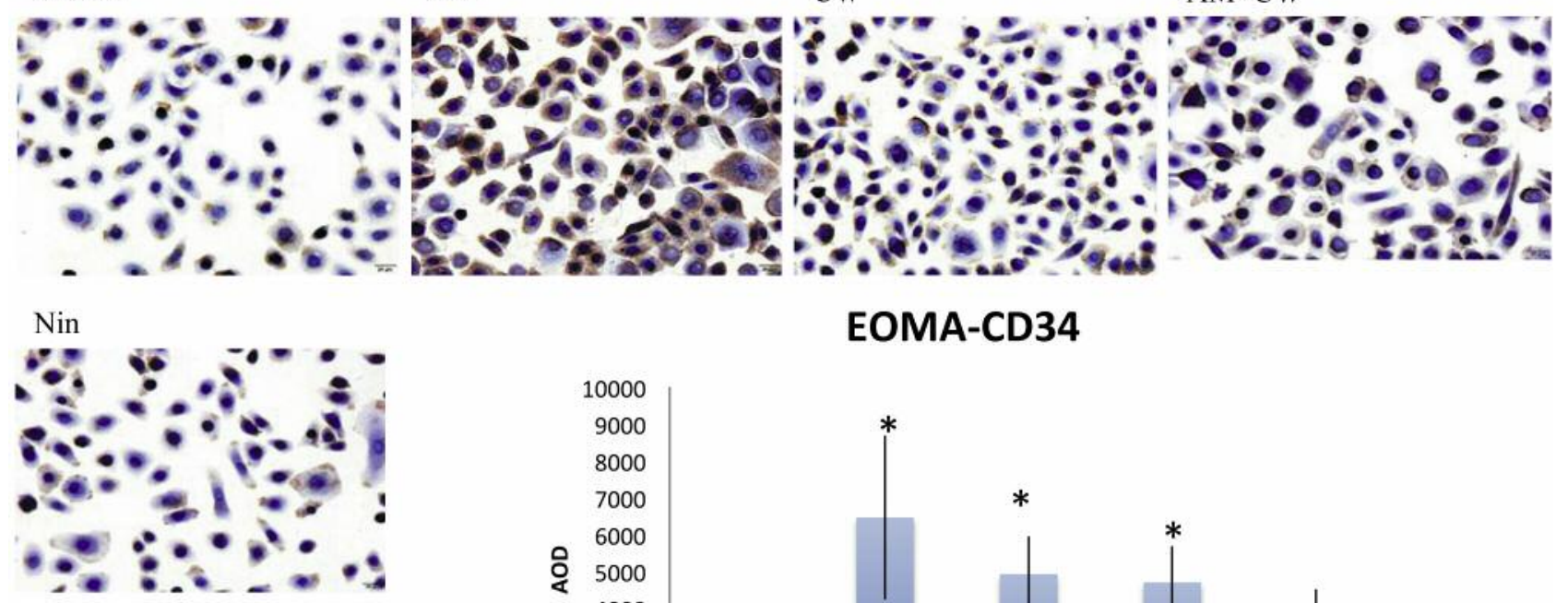

EOMA-CD34

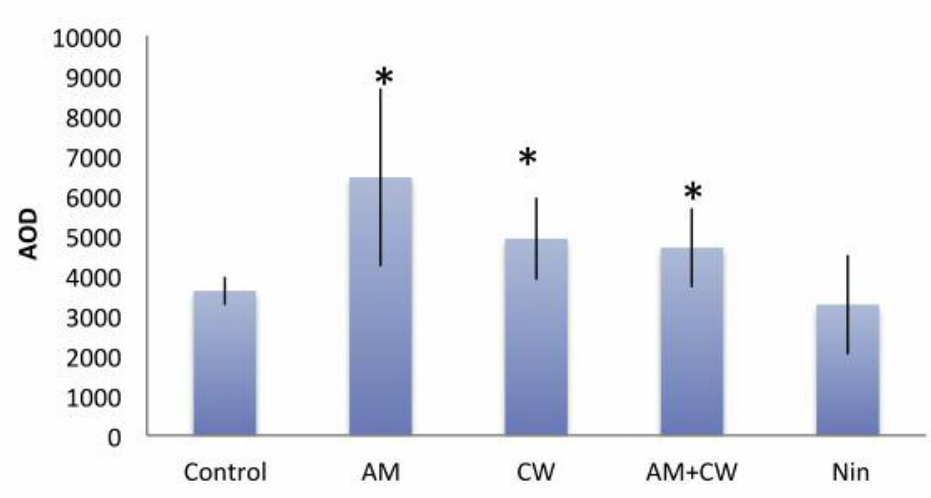

Figure 4. AM and CW increased expression of the angiogenic maker CD34. Immunocytochemistry was performed to measure protein expression of CD34. A. Representative microphotographs of immunocytochemical staining of TECs and quantification of CD34 expression in each treatment group. B. Representative microphotographs of immunocytochemical staining of EOMA cells and quantification of CD34 expression in each treatment group. Magnification $\times 400 .{ }^{*} p<0.01$, when compared to the control group. AM: Astragalus membranaceus. CW: Curcuma wenyujin. Nin: mintedanib; AOD: average optical density. 
A

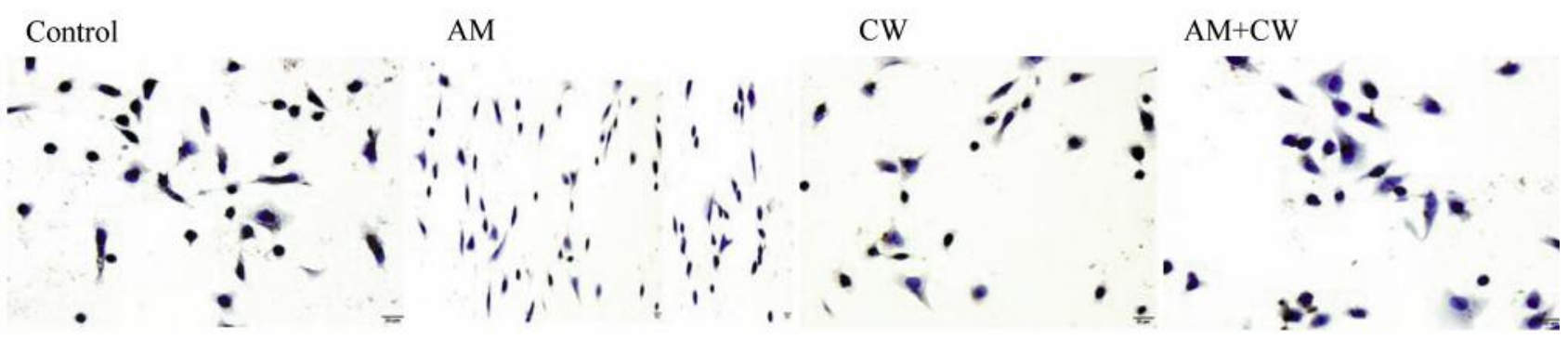

Nin

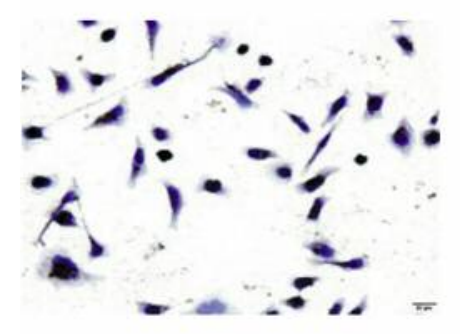

TECs-HIF-1 $\alpha$

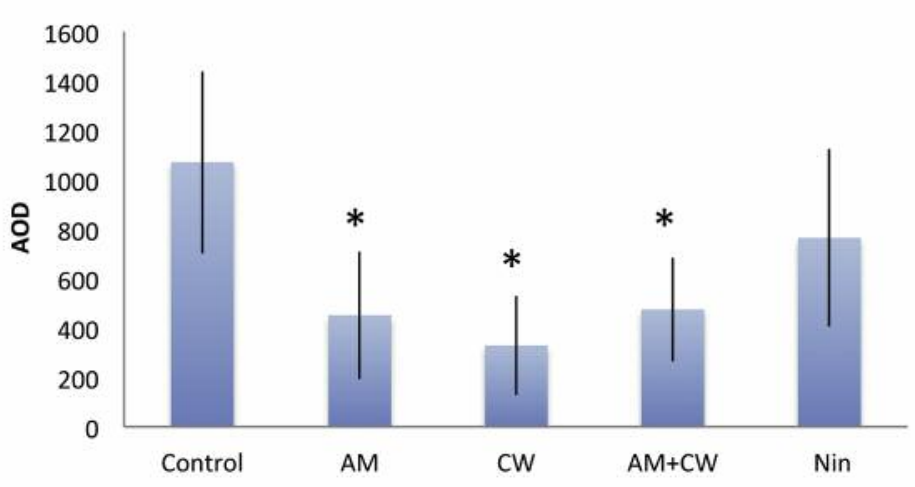

B
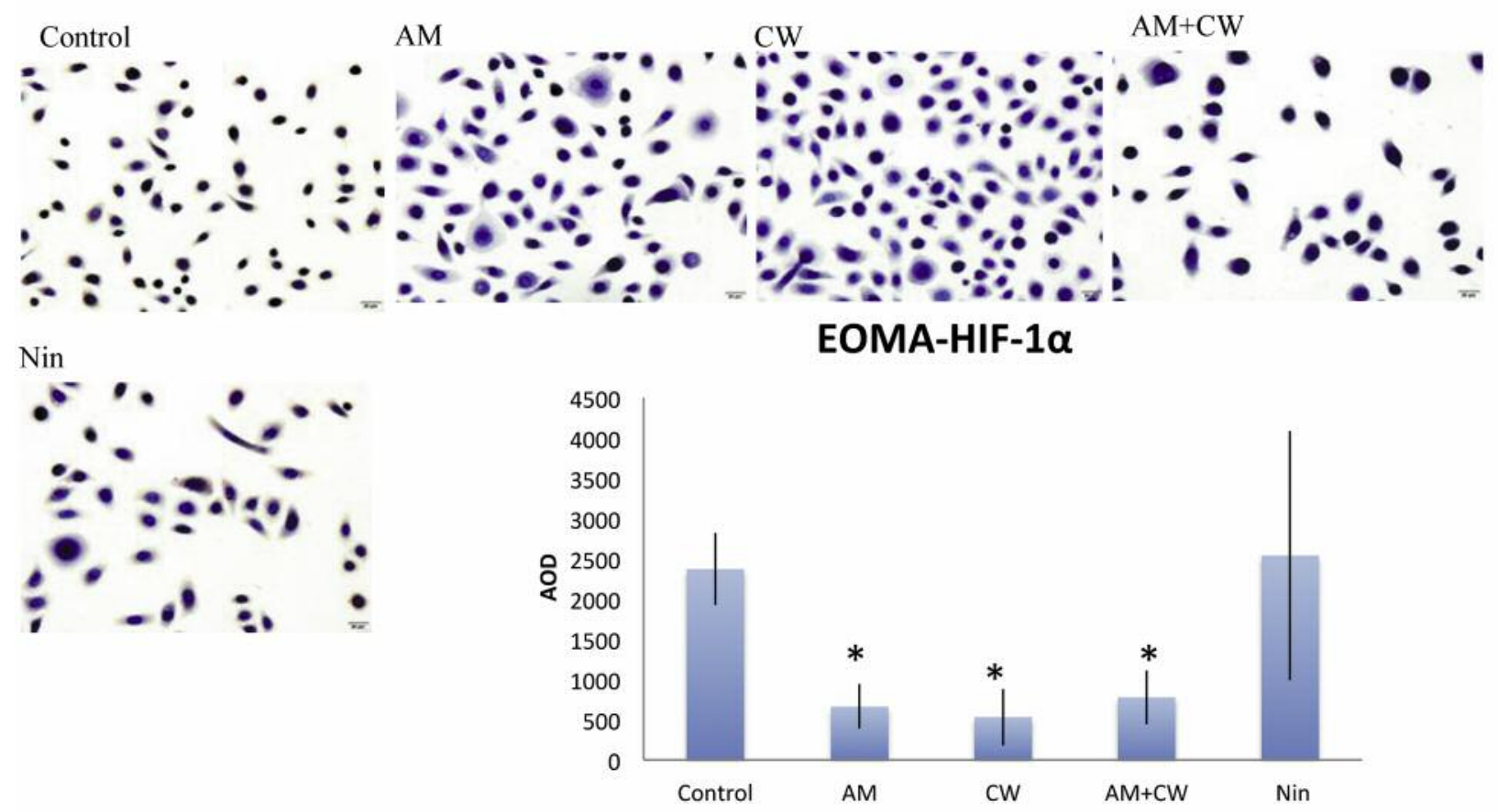

Figure 5. AM and CW reduced expression of hypoxia-inducible factor HIF1a. Immunocytochemistry was performed to measure protein expression of HIF 1a. A. Representative microphotographs of immunocytochemical staining of TECs and quantification of HIF1a expression in each treatment group. B. Representative microphotographs of immunocytochemical staining of EOMA cells and quantification of HIF Ia expression in each treatment group. Magnification $\times 400 .{ }^{*} p<0.01$, when compared to the control group. AM: Astragalus membranaceus; CW: Curcuma wenyujin; Nin: mintedanib; AOD: average optical density. 
and EOMA cells in a dose-dependent manner . In order to assess the effect of AM and $\mathrm{CW}$ on vascular normalization, the lowest dose $(0.18 \mathrm{mg} / \mathrm{ml}$ for AM and CW; $5 \mathrm{nM}$ for Nin) was selected for the subsequent experiments.

$A M$ and $C W$ enhanced endothelial network formation. The effect of AM and CW on tumor vascular normalization was assessed using a vascular tube formation assay. As shown in Figure $3 \mathrm{~A}$ and $\mathrm{B}, \mathrm{AM}, \mathrm{CW}$ and $\mathrm{AM}+\mathrm{CW}$ significantly enhanced endothelial network formation in TECs or EOMA cells as compared to the control $(p<0.05)$. However, Nin did not show any effect on endothelial network formation in TECs or EOMA cells compared to the control $(p>0.05)$.

Angiogenesis is a multi-step process requiring coordinated endothelial functions, such as cell migration, proliferation and extracellular matrix remodeling (24). The data presented here provide evidence in support of the normalization hypothesis of AM and CW on tumor angiogenesis.

Effect of $A M$ and $C W$ on the expression of angiogenic maker CD34 and hypoxia-inducible factor HIFla. Immunocytochemistry was performed to assess the effect of AM and $\mathrm{CW}$ on CD34 and HIF1a protein expression. As shown in Figure 4A and B, CD34 expression was significantly increased by $\mathrm{AM}, \mathrm{CW}$ and $\mathrm{AM}+\mathrm{CW}$ in both TECs and EOMA cells compared to the control $(p<0.05)$. Nin did not show any effect on CD34 expression in either TECs or EOMA cells compared to the control $(p>0.05)$. As shown in Figure 5A and B, AM, $\mathrm{CW}$ and $\mathrm{AM}+\mathrm{CW}$ significantly reduced HIF1a expression in both TECs and EOMA cells compared to the control $(p<0.01)$. HIF1a expression was not significantly affected by Nin in either TECs or EOMA cells compared to the control ( $p>0.05)$.

CD34 is a membrane glycoprotein found on the external surface of endothelial cells. During angiogenesis, CD34 protein is responsible for adhesion of leukocytes to the internal surface of the vascular wall and for migration of vascular endothelial cells (25).

HIF transcription factor controls the expression of numerous target genes contributing to tumor angiogenesis, invasion, metastasis, and treatment failure (26). In tumors, HIF1a stimulates the production of angiogenic factors, leading to an unrestricted angiogenesis that generates a chaotic vascular network with compromised tumor blood perfusion (27), resulting in a lack of oxygen delivery, thereby exacerbating tumor hypoxia (28). The present study showed increased CD34 and reduced HIF1a expression in AM and CW treated TECs, providing further evidence in support of the vascular normalization effects of AM and $\mathrm{CW}$ on tumor angiogenesis.

In conclusion, the present study showed that AM and $\mathrm{CW}$ promote vascular normalization in tumor-derived endothelial cells of human hepatocellular carcinoma. Increased CD34 and reduced HIF1a expression may be involved in the vascular normalization effect of AM and CW. The present study indicated the potential of $\mathrm{AM}$ and $\mathrm{CW}$ as tumor vascular normalization agents.

\section{Conflicts of Interest}

None of the Authors have a conflict of interest with regard to this study.

\section{Author's Contributions}

WENHUA Zang designed the study, analyzed the data and wrote draft manuscript; HUA BIAN and DECAI TANG participated study design; XIANZHANG HUANG and CHAOYUN ZHANG prepared test drugs; GANG YIN, LI HAN, PENGFEI HAO, SHENGCHEN DING and YU SUN performed experiments; ZHIJIAN YANG and ROBERT M. HOFFMAN revised the manuscript.

\section{Acknowledgements}

This research was supported by the National Natural Science Foundation of China Youth Fund (No. 81503270 and 81503267), the National Natural Science Foundation (No. 81073072 and 81373990), the Science and Technology Key Project of Henan Science and Technology Department (No. 182102310637), the Key Scientific Research Projects of Universities in Henan (No. 15A360011), the Henan Special Project of Chinese Medicine Scientific Research (No.2015ZY02004)

\section{References}

1 Flores A and Marrero JA: Emerging trends in hepatocellular carcinoma: focus on diagnosis and therapeutics. Clin Med Insights Oncol 8: 71-76, 2014. PMID: 24899827, DOI: 10.4137/ CMO.S9926

2 Pang R and Poon RTP: Angiogenesis and antiangiogenic therapy in hepatocellular carcinoma. Cancer Lett 242: 151-167, 2006. PMID: 16564617, DOI: 10.1016/j.canlet.2006.01.008

3 Abou-Alfa GK, Schwartz L, Ricci S, Amadori D, Santoro A, Figer A, De Greve J, Douillard JY, Lathia C, Schwartz B, Taylor I, Moscovici M and Saltz LB: Phase II study of sorafenib in patients with advanced hepatocellular carcinoma. J Clin Oncol 24: 4293-4300, 2006. PMID: 16908937, DOI: 10.1200/ JCO.2005.01.3441

4 Zhu AX, Blaszkowsky LS and Ryan DP: Phase II study of gemcitabine and oxaliplatin in combination with bevacizumab in patients with advanced hepatocellular carcinoma. J Clin Oncol 24: 1898-1903, 2006, PMID: 16622265, DOI: 10.1200/ JCO.2005.04.9130

5 Harper $\mathrm{J}$ and Moses MA: Molecular regulation of tumor angiogenesis: Mechanisms and therapeutic implications. EXS 96: 223-268, 2006. PMID: 16383021, DOI: 10.1007/3-7643-7378-4_10

6 Naumov GN, Akslen LA and Folkman J: Role of angiogenesis in human tumor dormancy: Animal models of the angiogenic switch. Cell Cycle 5: 1779-1787, 2006. PMID: 16931911, DOI: 10.4161/cc.5.16.3018

7 Verheul HM, Voest EE and Schlingemann RO: Are tumours angiogenesis-dependent. J Pathol 202: 5-13, 2004. PMID: 14694516, DOI: $10.1002 /$ path.1473 
8 Jain RK: Normalization of tumor vasculature: An emerging concept in antiangiogenic therapy. Science 307: 58-62, 2005. PMID: 15637262, DOI: 10.1126/science.1104819

9 Ellis LM and Hicklin DJ: VEGF-targeted therapy: Mechanisms of anti-tumour activity. Nat Rev Cancer 8: 579-591, 2008. PMID: 18596824, DOI: $10.1038 / \mathrm{nrc} 2403$

10 Watanabe M, Boyer JL and Crystal RG: Genetic delivery of bevacizumab to suppress vascular endothelial growth factorinduced high-permeability pulmonary edema. Hum Gene Ther 20: 598-610, 2009. PMID: 19254174, DOI: 10.1089/ hum.2008.169

11 Huang Y, Goel S, Duda DG, Fukumura D and Jain RK: Vascular normalization as an emerging strategy to enhance cancer immunotherapy. Cancer Res 73: 2943-2948, 2013. PMID: 23440426, DOI: 10.1158/0008-5472.CAN-12-4354

12 Klement G, Baruchel S, Rak J, Man S, Clark K, Hicklin DJ, Bohlen P and Kerbel RS: Continuous low-dose therapy with vinblastine and VEGF receptor-2 antibody induces sustained tumor regression without overt toxicity. J Clin Invest 105: R1524, 2000. PMID:10772661, DOI:10.1172/JCI8829

13 Tin, MM, Cho CH, Chan K, James AE and Ko JK: Astragalus saponins induce growth inhibition and apoptosis in human colon cancer cells and tumor xenograft. Carcinogenesis 28: 1347-1355, 2007. PMID: 17148504, DOI: 10.1093/carcin/bg1238

14 Law PC, Auyeung KK, Chan LY and Ko JK: Astragalus saponins down-regulate vascular endothelial growth factor under cobalt chloride-stimulated hypoxia in colon cancer cells. BMC Complement Altern Med 12: 160-167, 2012. PMID: 22992293 , DOI: $10.1186 / 1472-6882-12-160$

15 Liu X, Yang Y, Zhang X, Xu S, He S, Huang W and Roberts MS: Compound Astragalus and Salvia miltiorrhiza extract inhibits cell invasion by modulating transforming growth factor-beta/Smad in HepG2 cell. J Gastroenterol Hepatol 25: 420-426, 2010. PMID: 19793165, DOI: 10.1111/j.1440-1746.2009. 05981.x

16 Lim CB, Ky N, Ng HM, Hamza MS and Zhao Y: Curcuma wenyujin extract induces apoptosis and inhibits proliferation of human cervical cancer cells in vitro and in vivo. Integr Cancer Ther 9: 36-49, 2010. PMID: 20150221, DOI: 10.1177/153473 5409359773

17 Sun XY, Zheng YP, Lin DH, Zhang H, Zhao F and Yuan CS: Potential anticancer activities of furanodiene, a sesquiterpene from Curcuma wenyujin. Am J Chinese Med 37: 589-596, 2009. PMID: 19606517, DOI: 10.1142/S0192415X09007077

18 Xiao Y, Yang FQ, Li SP, Hu G, Lee SM and Wang YT: Essential oil of Curcuma wenyujin induces apoptosis in human hepatoma cells. World J Gastroenterol 14: 4309-4318, 2008. PMID: 18666318, DOI: $10.3748 /$ wjg. 14.4309

19 Tang D, Zang WH and Feng HH: The experimental study of proliferation inhibition and apoptosis induction of serum with different curcuma in ovarian cancer cell HO-8910. Lishizhen Med Materia Med Res 10: 2313-2315, 2013.
20 Yin G, Tang D, Dai J, Liu M, Wu M, Sun YU, Yang Z, Hoffman RM, Li L, Zhang S and Guo X: Combination efficacy of astragalus membranaceus and Curcuma wenyujin at differentstages of tumor progression in an imageable orthotopic nude mouse model of metastatichuman ovarian cancer expressing red fluorescent protein. Anticancer Res 35: 3193-3207, 2015. PMID: 26026079.

21 Xiong YQ, Sun HC, Zhang W, Zhu XD, Zhuang PY, Zhang JB, Wang L, Wu WZ, Qin LX and Tang ZY: Human hepatocellular carcinoma tumor-derived endothelial cells manifest increasedangiogenesis capability and drug resistance compared with normal endothelial cells. Clin Cancer Res 15: 4838-4846, 2009. PMID: 19638466, DOI: 10.1158/1078-0432.CCR-08-2780

22 St Croix B, Rago C and Velculescu V: Genes expressed in human tumor endothelium. Science 289: 1197-1202, 2000. PMID: 10947988, DOI: 10.1126/science.289.5482.1197

23 Hida $\mathrm{K}$ and Klagsbrun $\mathrm{M}$ : A new perspective on tumor endothelial cells: unexpected chromosome and centrosome abnormalities. Cancer Res 65: 2507-2510, 2005. PMID: 15805239, DOI: 10.1158/0008-5472.CAN-05-0002

24 Salani D, Taraboletti G, Rosano L, Di Castro V, Borsotti P, Giavazzi R and Bagnato A: Endothelin-1 induces an angiogenic phenotype in cultured endothelial cells and stimulates neovascularization in vivo. Am J Pathol 157: 1703-1711, 2000. PMID: 11073829, DOI:10.1016/S0002-9440(10)64807-9

25 Hollingsworth HC: Tumor angiogenesis in advanced stage ovarian carcinoma. Am J Pathol 147: 33-41, 1995. PMID: 7541612, DOI: 10.1111/j.1399-0039.1995.tb02492.x

26 Semenza GL: Hypoxia-inducible factors in physiology and medicine. Cell 148: 399-408, 2012. PMID:22304911, DOI: 10.1016/j.cell.2012.01.021

27 Escudier B, Eisen T, Stadler WM, Szczylik C, Oudard S and Staehler M: Sorafenib for treatment of renal cell carcinoma: final efficacy and safety results of the phase III treatment approaches in renal cancer global evaluation trial. J Clin Oncol 27: 33123318, 2009. PMID: 19451442, DOI: 10.1200/JCO.2008.19.5511

28 Carmeliet P and Jain RK: Principles and mechanisms of vessel normalization for cancer and other angiogenic diseases. Nat Rev Drug Discov 10: 417-427, 2011. PMID: 21629292, DOI: $10.1038 / \operatorname{nrd} 3455$
Received January 20, 2019

Revised February 16, 2019

Accepted February 18, 2019 